\title{
Dynamic rheology and microstructure of starch gels affected by triticale genomic composition and developing stage
}

\author{
Yaeel I. Cornejo-Ramírez ${ }^{1}$, Francisco J. Cinco-Moroyoqui ${ }^{1}$, Elizabeth Carvajal-Millán ${ }^{2}$, \\ Francisco Brown-Bojórquez ${ }^{3}$, Ema C. Rosas-Burgos ${ }^{1}$, Armando Burgos-Hernández ${ }^{1}$, \\ Oliviert Martínez-Cruz ${ }^{1}$, and Carmen L. Del Toro-Sánchez ${ }^{1}$ \\ ${ }^{1}$ Department of Food Research and Graduate Program (DIPA), University of Sonora, Hermosillo, Sonora 83000, Mexico \\ ${ }^{2}$ Laboratory of Biopolymers, CTAOA, Research Center for Food and Development, CIAD, A.C. Carretera a La Victoria Km. 0.6, \\ Hermosillo, Sonora 83304, Mexico \\ ${ }^{3}$ Department of Polymers, University of Sonora, Col. Centro, Blvd. Luis Encinas y Rosales S/N, Hermosillo, Sonora, C.P. 83000, \\ Mexico
}

Received January 28, 2018; accepted August 9, 2018

\begin{abstract}
Starches of developing triticale grains, differing in genome composition (complete AABBRR or substituted AABBDR), were evaluated in terms of starch granule distribution, dynamic rheological behaviour and microstructural characteristics on several days after anthesis. The starch granules were of an oblate spheroid shape for A-granules, and of a spherical shape for B-granules. However, those obtained from the complete triticale showed a larger diameter size. An X-ray diffraction analysis revealed the common A-type pattern of cereal starches from early development stages. A dynamic rheological analysis showed that the storage and loss moduli reached maximum levels in the temperature range of $71-86^{\circ} \mathrm{C}$ and dropped at around $90^{\circ} \mathrm{C}$. Starches from the complete triticale showed lower phase transition temperatures, compared to those obtained from the substituted genotype (56.1 \pm 0.3 and $60.3 \pm 0.8^{\circ} \mathrm{C}$, respectively). Scanning electron microscopy showed that the gels made with the starch of complete triticales were of a less dense sponge-like structure.

Keywords: triticale developing grains, starch, gels, rheology, microstructure
\end{abstract}

\section{INTRODUCTION}

Starch is the major polysaccharide and carbon reserve of plants (Hizukuri et al., 1981). Starch in the cereal endosperm is synthesized and accumulated to enhance plant and grain development. However, it is the grain-filling period that determines the final weight and quality of mature grains (Zhao et al., 2003).

\footnotetext{
*Corresponding author e-mail: javier.cinco@unison.mx
}

The major components of starch are glucose polymers, amylose and amylopectin. Amylose is a linear oligosaccharide made of D-glucose units bonded to each other through $\alpha$-1,4-glycosidic bonds with a degree of polymerization (DP) in the range of 500-6000 glucose residues. Amylopectin is a very large and highly branched chain molecule with a DP ranging from $3 \times 10^{5}$ to $3 \times 10^{6}$ glucose units, and it consists of $\alpha$-1,6-linked D-glucose units attached to $\alpha-(1,4)-$ bonds (Jeon et al., 2010).

Changes in the glucan chain length distribution or the degree of crystallinity can alter starch physico-chemical characteristics (Copeland et al., 2009). In the starch granule, amylose and amylopectin are arranged in the alternating amorphous and crystalline regions, respectively, forming what is known as the growth rings. Amylose molecules associated with large branches of amylopectin comprise the amorphous region of granules whereas short branches of amylopectin comprise the crystalline region, as a result of which a higher proportion of amylopectin in starch granules results in a higher crystallinity degree (Cheetham and Tao, 1998). Amylose exhibits the most useful functions as a hydrocolloid which forms gels and films. In contrast, amylopectin with long chains interferes with the interaction of amylose chains, preventing retrogradation, and leads to viscosity loss (Chung and Liu, 2009).

(C) 2019 Institute of Agrophysics, Polish Academy of Sciences 
Starch in cereal grains is synthesized in amyloplasts by four types of enzymes, i.e. ADP-glucose pyrophosphorylase, starch synthase, as well as branching and debranching enzymes (Cao et al., 2012). The action of these enzymes is influenced by cultivar and environmental conditions, which in turn affects the amount and size of the synthesized starch granules as well as the chain-length (Ulbrich et al., 2015), the amylose: amylopectin ratio (Altenbach et al., 2003; Cornejo-Ramírez et al., 2016; Jiamjariyatam et al., 2015) and the fine structure of amylopectin (Jane et al., 1999). All these properties influence the functional properties of starches, thus contributing to the final quality of food and non-food products. However, there is a continuous demand for new cultivars with improved agronomic characteristics, such as better yield and kernel size, improved nutritional properties and optimal performance under extreme environmental conditions. While the breeding of new and better cultivars through genetic crosses is required to overcome their demand, it is important to ensure that the expected improved quality has been reached through agronomic and rheological performance tests.

Triticale (X Triticosecale Wittmack) is a hybrid cereal crop created from a cross between durum wheat (Triticum durum) and rye (Secale cereale). Triticale varieties have been developed as complete (with genomic constitutions AABBRR and AABBDDRR) or substituted (with genomic constitutions AABBDR and AABBDDDR). The first substituted triticale, called Armadillo, was obtained as a result of a spontaneous crossing of triticale with an unknown Mexican semi-dwarf bread wheat. Taking advantage of the highly heritable good agronomic characteristics resulting from the fortuitous crossing, Armadillo materials were distributed by CIMMYT among plant breeders from all over the world, in order to be used for providing high fertility, better hectolitre weights and grain yield, insensitivity to photo-perforation, dwarfism, early maturity and good nutritional quality to the less promising triticales (Varughese et $a l .$, 1987). With further genetic improvements and research, both types of triticales have shown phenotypes and agronomic differences. Complete triticales are more adaptable and resistant to limiting conditions, showing higher productivity, both in fertile areas and in adverse conditions. However, substituted triticales have given rise to more varieties, since they are more stable and of better bakery quality (Mellado et al., 2008).

However, few studies have been conducted to compare and contrast the differences in certain physicochemical properties of starches among different triticale genotypes during grain development. To our knowledge, no research has been carried out that would focus on the dynamic rheological properties of starches affected by triticale genomic composition and grain developing stage. The aim of this research was to determine and compare the dynamic rheological and microstructural gel-forming properties of starches isolated from developing grains of two triticale genotypes on different days after anthesis. The results might yield further insights into whether immature and mature, complete and substituted, triticale grains could be best suited for commercial production.

\section{MATERIALS AND METHODS}

Seed samples of a complete triticale (Eronga variety, AABBRR genome) and a substituted triticale (Yoreme variety, AABBDR genome) were employed in this study. Grain samples of the two genotypes of triticale were planted during the 2012-2013 planting cycle at the same time and under the same environmental conditions, at the agriculture experiment station of the Agriculture and Livestock Department of the University of Sonora, Mexico (208 m above the sea level, with an average annual temperature of $24.2^{\circ} \mathrm{C}$ and an annual average rainfall of $280 \mathrm{~mm}$ ). A completely randomized complete block design with three replications (plots) for each triticale genotype was used.

Triticale spike samples were collected on selected days after anthesis (DAA). Eight spikes were cut from plants within each plot and shelled manually. Only developing and mature grains from the middle part of the spikes were collected and stored at $-70{ }^{\circ} \mathrm{C}$ until analysis.

Starch of triticale samples collected on different DAA was obtained from single kernels using the method proposed by Bettge et al. (1995) with modifications. Briefly speaking, the embryo and bran of the kernels were manually removed with a razor blade; the remaining parts of the kernels were lightly crushed between two sheets of wax paper and transferred to a standard $1.5 \mathrm{ml}$ Eppendorf polypropylene microcentrifuge tube. To prevent lumping, the solids were steeped twice with $500 \mu 1$ of petroleum ether for $30 \mathrm{~min}$ at room temperature with occasional gentle agitation. After centrifugation at 10,000 $\mathrm{g}$ for $2 \mathrm{~min}$ and removal of the solvent, the precipitate was steeped twice in $500 \mu \mathrm{l}$ of $100 \mathrm{mmol} \mathrm{l}^{-1} \mathrm{NaCl}$ at room temperature for 30 min with occasional gentle agitation. Gluten was formed by kneading the endosperm inside the microcentrifuge tube, with the use of a Teflon micro-spatula, and then manually removed. The starch was washed twice with $500 \mu \mathrm{l}$ of deionised water to remove excess of salt, following which it was centrifuged at $10,000 \mathrm{~g}$ for $2 \mathrm{~min}$, re-suspended in $1 \mathrm{ml}$ of acetone and dried at ambient temperature.

The size distribution of defatted starch granules was measured using laser diffraction in a Coulter LS 100Q (Beckman Coulter, Miami, FL, USA). Big starch granules $(>6 \mu \mathrm{m})$ are commonly referred to as A-type starch granules, whereas the small ones $(\leq 6 \mu \mathrm{m})$ are known as B-type starch granules. For analysis, a small quantity $(20-30 \mathrm{mg}$ ) of starch was vortexed in $2 \mathrm{ml}$ of deionised water and pumped through the optical chamber. A GB500 standard, consisting of a glass bead sample (500 $\mu \mathrm{m}$ nominal mean particle size), was used as a reference. 
The crystallinity percent of triticale starches was determined using the X-ray diffraction methodology proposed by Song and Jane (2000). Starch samples were equilibrated in a $100 \%$ relative humidity chamber for $24 \mathrm{~h}$ at $27^{\circ} \mathrm{C}$. $\mathrm{X}$-ray diffraction patterns (XRD) were obtained with nickel foil-filtered $\mathrm{Cu} \mathrm{K} \alpha$ radiation, using a Rigaku RINT-2000 diffractometer (Tokyo, Japan), at $27 \mathrm{~mA}$ and $50 \mathrm{kV}$. The scanning region or the two-theta angle $(2 \theta)$ ranged from 5 to $50^{\circ}$ with a $0.05^{\circ}$ step size and a count time of $2 \mathrm{~s}$. The crystalline percent values were calculated according to Hayakawa et al. (1997), by means of the following equation: Crystallinity percent $=\mathrm{Ac} /(\mathrm{Ac}+\mathrm{Aa}) 100$, where $\mathrm{Ac}$ and Aa correspond to the crystallinity and amorphous areas, respectively, on the X-ray diffractograms.

Rheology is a convenient tool to study starch gelation since a physical gel is formed during starch gelatinization. The gelatinization process can be analyzed by monitoring the rheological properties using a rheometer. The gelatinization properties of the starches isolated from the developing grains of the two triticale genotypes were studied using a stress-controlled Discovery Hybrid Rheometer HR-2 (TA Instruments, New Castle, DE, USA) equipped with two parallel plates (Peltier Plate Steel-104556) with $40 \mathrm{~mm}$ in diameter. A volume of $1.5 \mathrm{ml}$ of $10 \%$ starch-water suspensions was routinely placed on the centre of the bottom plate while the upper plate was immediately lowered until the final gap of $1 \mathrm{~mm}$ was reached. The edges of the plates were covered with paraffin oil in order to prevent dehydration of the samples by evaporation. Starch samples were examined in the angular frequency sweep scan range of $0.01-60 \mathrm{~Hz}$ at a constant strain of $1 \%$. The start temperature was $25^{\circ} \mathrm{C}$, and a ramp temperature of $5^{\circ} \mathrm{C} \mathrm{min}^{-1}$ was used until the final temperature of $90^{\circ} \mathrm{C}$ was reached. After $30 \mathrm{~s}$ of releasing the stress, the samples were cooled to $25^{\circ} \mathrm{C}$ at a cooling rate of $5^{\circ} \mathrm{C} \mathrm{min}^{-1}$. After $300 \mathrm{~s}$ of soaking time, the gels were frozen at $-20^{\circ} \mathrm{C}$, lyophilized and stored for further analysis. The rheological parameters elastic modulus $\left(\mathrm{G}^{\prime}\right)$ and viscous modulus $\left(\mathrm{G}^{\prime \prime}\right)$ were obtained at the frequency sweep range indicated above. The phase transition temperature $\mathrm{T}_{0}$, i.e. the crossover where the G' and G" values started to increase at the same temperature and representing the solto-gel transition, was determined in the dynamic modulus spectrum (G' and G') during heating (Ulbrich et al., 2015).

Scanning Electron Microscopy (SEM) was used to analyze the microstructure of the triticale starch gels using the method proposed by Jane et al. (1994). The lyophilized starch gels were placed on a $13 \mathrm{~mm}$ silver tape, metalshadowed with gold/palladium (60/40) (Sputter coater SPI-Module; West Chester, PA, USA) and mounted on a brass disk. Starch samples were analyzed using a magnification of $1500 \mathrm{X}$ under low vacuum, using a JEOL JSM-5400LV scanning electron microscope (Peabody, MA, USA), at an acceleration voltage of $15 \mathrm{kV}$.
All data were obtained from three independent experiments and expressed as mean \pm standard deviation of triplicates. Data were subjected to one-way analysis of variance (ANOVA) following general model procedures. A comparison of sample means was performed by means of the Tukey's test with the SAS program (SAS, 2005). In all cases, the mean values were considered significantly different at $\mathrm{p} \leq 0.05$.

\section{RESULTS AND DISCUSSION}

The granule size distribution of the starch strongly influences its physicochemical properties and functionality. In this study, the size distributions of starch granules of developing triticale grains were measured using laser diffraction. Table 1 shows the size distributions of starch granules of complete (Eronga) and substituted (Yoreme) triticale developing grains. Both triticale genotypes showed a bimodal starch granule distribution similar to that reported previously (Cornejo-Ramírez et al., 2015) with oblate spheroid shape for A-granules and spherical shape for B-granules (Bechtel et al., 1990). In general, A- and B-type starch granules of both triticale genotypes increased in size during grain development, with differences in size distribution values as well as in granules volume percent observed at all stages of development. However, A- and B-type starch granules of the complete triticale showed bigger sizes than those obtained from the substituted genotype throughout the course of the developing period of grains. The data also show that the A- and B-type starch granules of the complete triticale grew faster and reached larger diameters than the granules of the substituted triticale. A similar behaviour was observed in wheat starch granules during development (Bechtel et al., 1990; Kim et al., 2003).

Starch molecules arrange themselves in the grain in crystalline granules. Amylose molecules comprise the amorphous region of granules, whereas amylopectin molecules with short branches comprise the crystalline region. Crystallinity of starch granules has been directly associated with amylopectin concentration (Cheetham and Tao, 1998) and inversely related to onset temperature $\left(\mathrm{T}_{0}\right)$, peak temperature $\left(T_{p}\right)$ and enthalpy $(\Delta H)$ (Kim et al., 2003). There are three types of crystalline structures, i.e. A-type found in cereal starches, B-type found in tubers and C-type present in legumes (Singh et al., 2003). In our study, the starches presented the typical A-type X-ray diffraction pattern (Fig. 1) observed in cereal starches (Kim et al., 2015). The diffractograms of triticale starches showed peaks at 15, 17.1, 18 and $23^{\circ}$ from the early stage until their maturity.

The starch samples displayed the same X-ray diffraction pattern because their chemical composition and physicochemical properties are similar. Also, intensities of each peak of the starches isolated from developing grains on 16, 22 and 31 DAA are similar, whereas the intensities of the peaks of these starch samples are different from those obtained from mature grains. This suggests that the 
T a b I e 1. Starch granule size distribution and volume (\%) of A- and B-type starch granules obtained from complete (Eronga) and substituted (Yoreme) triticales during grain development on different days after anthesis (DAA)

\begin{tabular}{ccccc}
\hline & \multicolumn{3}{c}{ A-type } & B-type \\
\cline { 2 - 5 } DAA & Size $(\mu \mathrm{m})$ & Volume $(\%)$ & Volume $(\%)$ \\
\hline & & Complete triticale (Eronga) $(\mu \mathrm{m})$ & $13.7 \pm 0.06 \mathrm{bC}$ \\
22 & $6.7-23$ & $86.3 \pm 0.06 \mathrm{aB}$ & $0.96-3.7$ & $14.5 \pm 0.20 \mathrm{bB}$ \\
31 & $8.5-30$ & $85.5 \pm 0.20 \mathrm{aC}$ & $0.98-4.5$ & $12.4 \pm 0.20 \mathrm{bD}$ \\
40 & $14-36$ & $87.6 \pm 0.20 \mathrm{aA}$ & $1.5-5.2$ & $19.6 \pm 0.03 \mathrm{bA}$ \\
16 & $18-40$ & $80.4 \pm 0.03 \mathrm{a} D$ & $2.0-11.0$ & $13.3 \pm 0.05 \mathrm{bC}$ \\
22 & & & & $12.0 \pm 0.09 \mathrm{bD}$ \\
31 & $6.7-20$ & Substituted triticale (Yoreme) & $0.94-3.4$ & $13.7 \pm 0.30 \mathrm{bB}$ \\
40 & $9.0-24$ & $86.7 \pm 0.05 \mathrm{aB}$ & $0.96-3.6$ & $25.4 \pm 0.05 \mathrm{bA}$ \\
\hline
\end{tabular}

Mean values are expressed in percentage \pm standard deviation. Values followed by the same lowercase letter in the same row and capital letter in the same column are not significantly different $(\mathrm{p} \leq 0.05, \mathrm{n}=3)$.

amylopectin shapes of starches from mature grains are different from those of starches isolated from immature grains. Based on the results provided by the X-ray diffraction analysis of inorganic crystals, carried out by Inoue and Hirasawa (2013), the total area, and the longitude and latitude of crystals affect the X-ray peak intensities. As shown by Cornejo-Ramírez et al. (2016), reduction in the intensity of the X-ray diffraction patterns of triticale starches might be due to reduction in the volume of the A-type starch granules at the end of the maturation period. Additionally, the crystallinity of those starches increases due to a compaction of the amylopectin chains to form the crystalline areas.

A comparison of the crystallinity values observed along the whole developing period showed that the complete and substituted triticale starches were similar, reaching final values of $36.1 \%$ on 40 DAA (Table 2). Furthermore, an analysis of the crystallinity values of each triticale throughout the developing period showed that the complete triticale did not exhibit significant differences in crystallinity from 16 to 31 DAA, but on 40 DAA displayed a value significantly higher than those observed at early stages. In contrast, the starch granules of the substituted triticale showed continuous changes in crystallinity until the end of the maturity period. The final values in crystallinity of the triticale starch granules were similar to those observed in the starch of wheat (Zhang et al., 2013), as well as barley and triticale (Ao and Jane, 2007), though they were higher than those reported for waxy wheat (Yoo and Jane, 2002). Differences in percent crystallinity values of starches from several sources have been attributed to the amylose (Yoo and Jane, 2002), lipid (Finnie et al., 2009), and amylopectin contents and amylopectin chain length, as well as the orientation of amylose double helices (Zhang et al., 2013).
The gelatinization process triggers several changes in the physicochemical properties of starches which be measured with a rheometer. At the sol-gel transition, the starch solution loses its liquid properties and begins to turn into a solid substance. In this study, the gelatinization mechanism of starches from complete (Eronga) and substituted (Yoreme) developing triticale grains was studied by means of a dynamic mode rheological analysis. Oscillatory measurements were performed within the linear viscoelasticity region and the results provided information on the dynamic mechanical properties of the starch gels evaluated as the elastic modulus $G^{\prime}$ and the viscous modulus $G$ '. Figure 2A,B shows the evolution of the elastic $\left(G^{\prime}\right)$ and viscous $\left(G^{\prime \prime}\right)$ moduli of starch granules from the complete and substituted triticales, respectively, as a function of temperature. The changes in G' and G' of the 16 to 40 DAA starch dispersions displayed similar behaviour. In general, for both triticale genotypes the $\mathrm{G}^{\prime}$ and $\mathrm{G}$ " moduli values reached maximum levels in the temperature range of $71-86^{\circ} \mathrm{C}$, and dropped with further heating at around $90^{\circ} \mathrm{C}$. Both moduli showed the same profile; however, G' displayed higher values than G" in both triticale genotypes, although those of the complete genotype were higher than the substituted genotype. Higher values of G' and G' have also been observed in corn (Kaur et al., 2008) and wheat (Ulbrich et al., 2015) starch dispersions. The effect of frequency on the elastic modulus G' and viscous modulus G" of the starch of developing complete (Eronga) and substituted (Yoreme) triticale grains are shown in Fig. 2C, D. All samples showed a solidlike system. The values of G' and G' moduli of all triticale starches were independent of frequency, which is typical of 'true gels' (Sang et al., 2008). Also, all starch samples showed G'values higher than those of G', and were higher 



Fig. 1. X-ray diffraction of the starch of complete (AABBRR) triticale on 16, 22, 31, and 40 DAA (A, B, C and D, respectively) and substituted (AABBDR) triticale on 16, 22, 31, and 40 DAA (E, F, G and H, respectively). 
Table 2. Crystallinity percent of starch granules from complete (AABBRR) and substituted (AABBDR) developing triticale grains on different days after anthesis (DAA)

\begin{tabular}{ccc}
\hline & \multicolumn{2}{c}{ Crystallinity (\%) } \\
\cline { 2 - 3 } DAA & $\begin{array}{c}\text { Complete triticale } \\
\text { (Eronga) }\end{array}$ & $\begin{array}{c}\text { Substituted triticale } \\
\text { (Yoreme) }\end{array}$ \\
\hline 16 & $26.5 \pm 0.7 \mathrm{aB}$ & $27.0 \pm 0.6 \mathrm{aC}$ \\
22 & $27.3 \pm 0.4 \mathrm{aB}$ & $28.1 \pm 0.3 \mathrm{aBC}$ \\
31 & $28.6 \pm 0.7 \mathrm{aB}$ & $29.2 \pm 0.4 \mathrm{aB}$ \\
40 & $36.1 \pm 0.1 \mathrm{aA}$ & $36.8 \pm 0.3 \mathrm{aA}$ \\
\hline
\end{tabular}

Explanations as in Table 1.

A

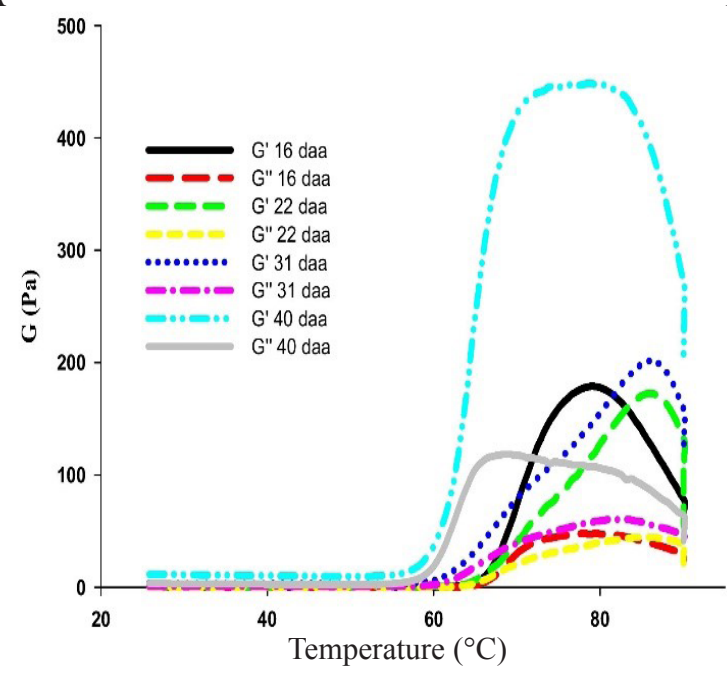

C

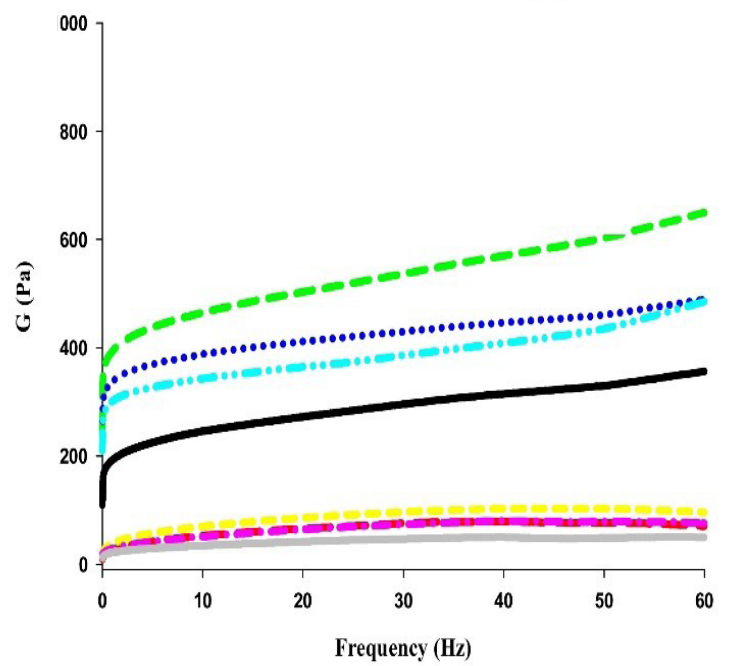

in the complete triticale than in the substituted one, suggesting a gel-like behaviour similar to that observed in the starch of corn (Kaur et al., 2008), sorghum (Sang et al., 2008) and wheat (Ulbrich et al., 2015). Furthermore, the starch of both triticale genotypes exhibited very similar G" values, suggesting that its viscous contribution to the gel structure was similar throughout its synthesis in the developing grains.

The sol-gel transition temperature $T_{0}$ was determined at the crossover point of G' and G'. Table 3 shows the $T_{0}$ values of starches from complete (Eronga) and substituted (Yoreme) developing triticale grains. The starches of the developing complete triticale grains showed significantly lower $\mathrm{T}_{0}$ values than those of the substituted triticale throughout the developing period. The $\mathrm{T}_{0}$ values of complete and substituted triticale were the highest on 16 DAA

B

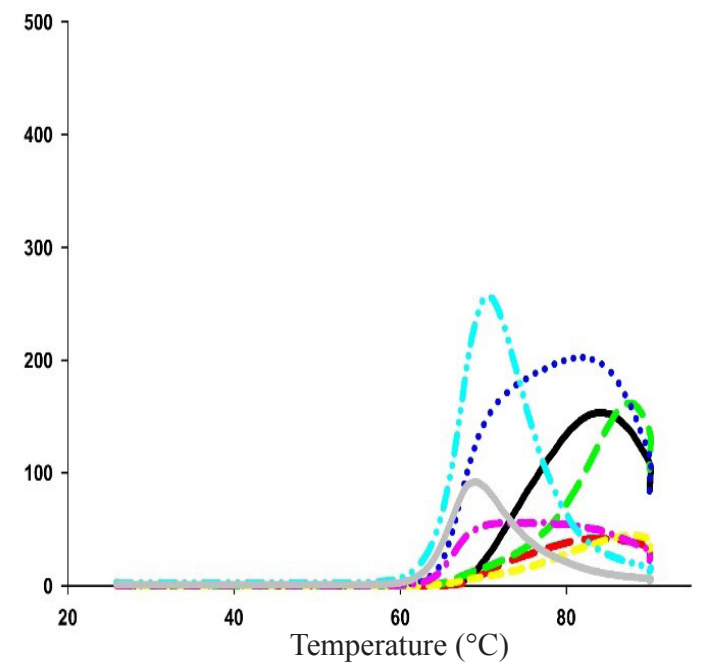

D 1000

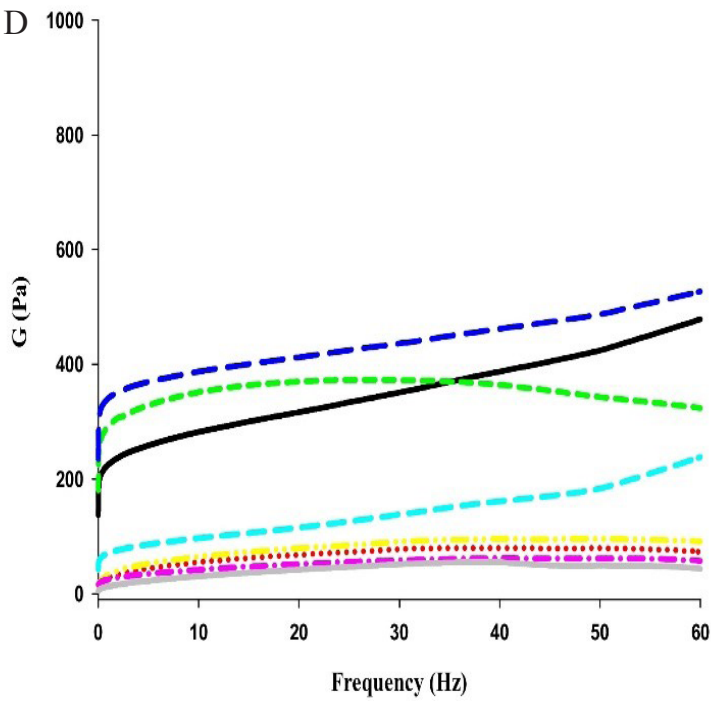

Fig. 2. Changes in elastic G' and viscous G" modulus during heating (the angular frequency sweep scan range of 0.01-60 Hz; constant strain $1 \%$; ramp temperature $5^{\circ} \mathrm{C} \mathrm{min}^{-1}$; start temperature $25^{\circ} \mathrm{C}$; final temperature $90^{\circ} \mathrm{C}$ ) of $10 \%$ starch suspensions of the complete triticale (AABBRR) and the substituted triticale (AABBDR) by the effect of temperature (A and B) and frequency (C and D) using a stress-controlled Discovery Hybrid Rheometer HR-2 equipped with two parallel plates with $40 \mathrm{~mm}$ in diameter. 
Table 3. Sol-to-gel phase transition temperature $\left(T_{0}\right)$, degree of polymerization of amylose and apparent amylose content of starches extracted from complete (AABBRR) and substituted (AABBDR) developing triticale grains on different days after anthesis (DAA)

\begin{tabular}{|c|c|c|c|}
\hline DAA & $\begin{array}{l}\text { Transition temperature } \\
\left(\mathrm{T}_{0},{ }^{\circ} \mathrm{C}\right)\end{array}$ & $\begin{array}{c}\text { Degree of polymerization } \\
\text { of amylose* }\end{array}$ & Apparent amylose $(\%)^{*}$ \\
\hline \multicolumn{4}{|c|}{ Complete triticale } \\
\hline 16 & $63.9 \pm 0.4 \mathrm{aB}$ & $375 \pm 49 a$ & $13.5 \pm 0.2 b$ \\
\hline 22 & $63.6 \pm 0.5 \mathrm{aB}$ & $405 \pm 36 a$ & $11.7 \pm 0.7 \mathrm{a}$ \\
\hline 31 & $59.5 \pm 0.7 \mathrm{bB}$ & $811 \pm 42 \mathrm{a}$ & $16.5 \pm 0.8 \mathrm{a}$ \\
\hline 40 & $56.1 \pm 0.3 \mathrm{cB}$ & $1549 \pm 42 \mathrm{a}$ & $23.5 \pm 0.8 \mathrm{a}$ \\
\hline \multicolumn{4}{|c|}{ Substituted triticale } \\
\hline 16 & $66.3 \pm 0.3 \mathrm{aA}$ & $254 \pm 38 b$ & $14.1 \pm 0.2 \mathrm{a}$ \\
\hline 22 & $65.2 \pm 0.2 \mathrm{aA}$ & $287 \pm 43 b$ & $11.3 \pm 0.7 \mathrm{a}$ \\
\hline 31 & $62.7 \pm 0.3 \mathrm{bA}$ & $756 \pm 41 b$ & $15.9 \pm 0.6 \mathrm{~b}$ \\
\hline 40 & $60.3 \pm 0.8 \mathrm{cA}$ & $1313 \pm 62 b$ & $22.1 \pm 0.7 \mathrm{~b}$ \\
\hline
\end{tabular}

Values are expressed as mean \pm standard deviation. Values followed by the same: lowercase letter and capital letter in the same column are not significantly different for similar DAA $(\mathrm{p} \leq 0.5)$. *Data taken from Cornejo-Ramírez et al. (2016).

$\left(63.9 \pm 0.4\right.$ and $66.2 \pm 0.3^{\circ} \mathrm{C}$, respectively) and $22 \mathrm{DAA}$ $\left(63.6 \pm 0.5\right.$ and $65.2 \pm 0.2^{\circ} \mathrm{C}$, respectively), and decreased with time, reaching the lowest values on 40 DAA $(56.1 \pm$ 0.3 and $60.3 \pm 0.8^{\circ} \mathrm{C}$, respectively). The highest $\mathrm{T}_{0}$ values were observed in starches of the substituted triticale from the 16 DAA and to 22 DAA with no significant differences. However, the transition $\mathrm{T}_{0}$ values determined in this research for both triticale starches were lower than those reported for acid-modified wheat $\left(69.4^{\circ} \mathrm{C}\right)$, potato $\left(80^{\circ} \mathrm{C}\right)$ and pea $\left(80^{\circ} \mathrm{C}\right)$ (Ulbrich et al., 2015). Yet, they fell within the range of values reported for normal corn $\left(65.7^{\circ} \mathrm{C}\right)$ (Kaur et al., 2008) and normal wheat $\left(46-57.1^{\circ} \mathrm{C}\right)$ starches (Sasaki et al., 2000). The differences in $\mathrm{T}_{0}$ of starches from diverse cereal cultivars might be due to variations in the granular structures, degree of polymerization and molecular architecture of amylopectin (Singh et al., 2003).

The higher percent crystallinity of the starch makes the granules more resistant to gelatinization because the longer chains of amylopectin require higher temperatures to dissociate completely, while the opposite occurs for amylose (Yamin et al., 1999). Also, a starch with high amylose content has a more amorphous region and, therefore, a less crystalline region, as a result of which low temperatures are needed to achieve gelatinization (Sasaki et al., 2000). In our study, the starches from the substituted triticale genotypes showed, in general, higher crystallinity values throughout the developing period, although no significant statistical differences were observed.

The $T_{0}$ values were strongly influenced by genotype, considering that the starches of the developing grains of the complete triticale Eronga showed lower transition tempera- tures $\left(\mathrm{T}_{0}\right)$ and were related to higher amylose contents and higher amylose DP, in contrast to those of the substituted triticale Yoreme (Table 3).

The gels made with the starch of triticales developed on 16 DAA showed large air cells of sponge-like structures (Fig. 3), which has also been observed in waxy corn (Kaur et al., 2008) and corn starch (Alishahi et al., 2015). However, both gels displayed some differences. The starch gel of complete triticale (Eronga) showed an internal structure more similar to the gels of corn starch, while the starch gel of the substituted triticale (Yoreme) displayed an internal structure showing small air cells within large ones.

The gels made with the triticale starch samples on 22 DAA formed a closed network, creating small cells of sponge-like structures, similar to the internal structure of the gels made with normal corn starch (Kaur et al., 2008). The internal structure displayed by all these gels might be due to higher DP of amylose (Table 3) that could make a thick matrix, capable of filling the space between the remnants, resulting in a porous structure due to the formation of voids, similar to a honeycomb-like structure. The differences in the gel microstructures might be due to the differences in the physicochemical characteristics of the developing starch granules to make the gels. The starches of complete and substituted triticales differed in terms of the DP of amylose (Cornejo-Ramírez et al., 2016), size and volume percent of A- and B-starch granules (Table 1) at this stage of development.

The gels made with the starch samples of the triticale collected on 31 DAA formed a network with larger cells of sponge-like structures, though not as large as those of the gel network made with the starch formed on 16 DAA. The internal structures of the gels were similar to those made 

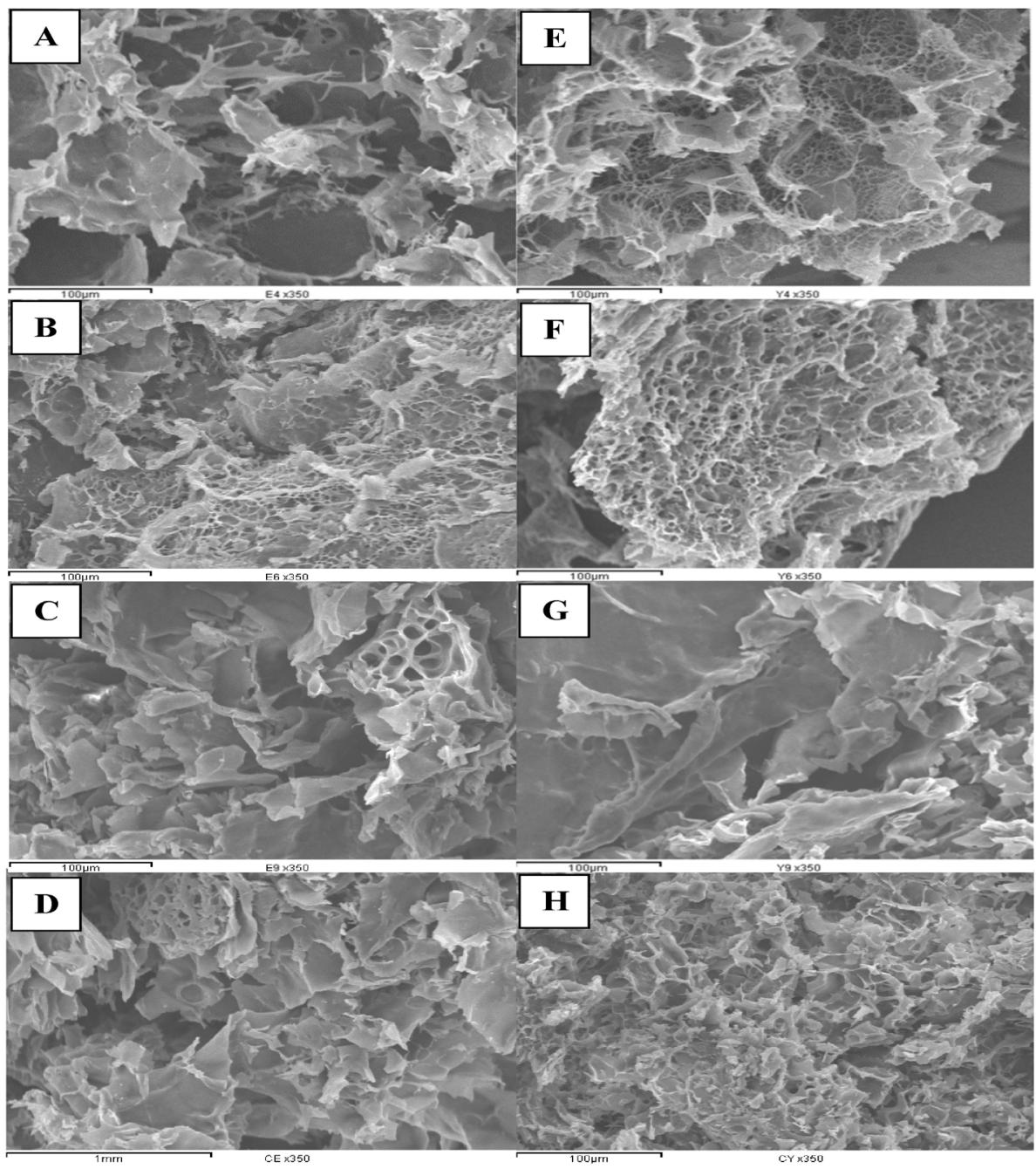

Fig. 3. Scanning electron micrographs of starch gel samples prepared from starches of developing grains of a complete triticale (AABBRR) on 16, 22, 31, and 40 DAA (A, B, C and D, respectively), and of a substituted triticale (AABBDR) on 16, 22, 31, and 40 $\operatorname{DAA}(\mathrm{E}, \mathrm{F}, \mathrm{G}$ and $\mathrm{H}$, respectively) using a magnification of $350 \mathrm{x}$.

with waxy corn starch (Kaur et al., 2008); however, the starch gel of the complete triticale showed similar areas to the gels made with wheat starch-wheat fibre (Sun et al., 2015) and corn starch (Alishahi et al., 2015).

The gels made with the triticale starch samples at maturity (40 DAA) showed differences among them in their internal structures. The gel made with starch of complete triticale displayed an internal structure with a minor dense honeycomb structure, with reduced internal pores, and a large lamellar structure similar to the gels made with wheat starch (Sun et al., 2015). Therefore, large starch gels have the advantage in competing for water molecules forming a strong network structure that enhances the mechanical properties of noodles, vermicelli and sheet jelly (Alishahi et al., 2015). In contrast, the gel made with the starch of substituted triticale displayed more similarities to the gels prepared with wheat starch (Sun et al., 2015) and normal corn starch (Kaur et al., 2008). The corn starch gels showed low peak viscosity, G', G', and Tp and less pronounced changes in the rheological parameters within the frequency sweeps, low stability of pastes at low temperatures and low resistant to retrogradation. The gels made with substituted triticale showed the same rheological behaviour as the corn starch gels, and they could have low cohesiveness and high values of springiness, hardness, gumminess and viscosity (Sun et al., 2015).

\section{CONCLUSIONS}

1. The results showed that the starches of the complete genotype displayed different gel properties than those obtained from the substituted genotype, due to differences in the molecular structure of their amylose and amylopectin, synthesized on different DAA during grain developing.

2. The complete triticale developed bigger and more crystalline A- and B-type starch granules than the substituted triticale. Although no significant differences in crystallinity were observed between the starches collected $\mathrm{n}$ different DAA, the substituted triticale showed higher crystallinity values, which coincided with the low amylose content reported in a previous study. 
3. Dynamic rheology determinations revealed that the complete triticale displayed higher values of elastic $G^{\prime}$ and viscous G' moduli than the substituted triticale.

4. Starches of the complete triticale collected on several DAA showed lower phase transition temperature values than those obtained from the substituted one, suggesting lower gelatinization temperatures.

5. The microstructure of gels prepared from starches extracted from the complete triticale grains displayed a denser internal structure.

Conflict of interest: The authors have no conflict of interest to declare.

\section{ACKNOWLEDGEMENTS}

The authors wish to thank the Wheat Collection Wellhausen-Anderson Plant Genetic Resource Center of the International Maize and Wheat Improvement Center, CIMMYT-México for kindly donating the triticale seeds used in this study. Author Yaeel I. Cornejo-Ramírez acknowledges the National Council for Science and Technology (CONACyT, Mexico) for providing a doctoral fellowship.

\section{REFERENCES}

Alishahi A., Farahnaky A., Majzoobi M., and Blanchard C.L., 2015. Physicochemical and textural properties of corn starch gels: Effect of mixing speed and time. Food Hydrocoll., 45, 55-62.

Altenbach S.B., DuPont F.M., Kothari K.M., Chan R., Johnson E.L., and Lieu D., 2003. Temperature, water and fertilizer influence the timing of key events during grain development in a US spring wheat. J. Cereal Sci., 37, 9-20.

Ao Z. and Jane J., 2007. Characterization and modeling of the A- and B-granule starches of wheat, triticale, and barley. Carbohyd. Polym., 67, 46-55.

Bechtel D.B., Zayas I., Kaleikau L., and Pomeranz Y., 1990. Size distribution of wheat starch granules during endosperm development. Cereal Chem., 67, 59-63.

Bettge A.D., Morris C.F., and Greenblatt G.A., 1995. Assessing genotypic softness in single wheat kernels using starch granule-associated friabilin as a biochemical marker. Euphytica, 86, 65-72.

Cao Y., Hu W., and Wang C., 2012. Relationship among the key enzymatic activities involved in starch synthesis and amylopectin chain distributions in developing wheat grain. Afr. J. Biotechnol, 11(4), 805-814.

Cheetham N.W.H. and Tao L., 1998. Variation in crystalline type with amylose content in maize starch granules: an X-ray powder diffraction study. Carbohyd. Polym., 36(4), $277-284$.

Chung H.J. and Liu Q., 2009. Impact of molecular structure of amylopectin and amylose on amylose chain association during cooling. Carbohyd. Polym., 77(4), 807-815.

Copeland L., Blazek J., Salman H., and Tang M.C., 2009. Form and functionality of starch. Food Hydrocoll., 23(6), 1527-1534.
Cornejo-Ramírez Y.I., Cinco-Moroyoqui F.J., Ramírez-Reyes F., Rosas-Burgos E.C., Osuna-Amarillas P.S., WongCorral F.J., Borboa-Flores J., and Cota-Gastélum A.G., 2015. Physicochemical characterization of starch from hexaploid triticale (X Triticosecale Wittmack) genotypes. CyTA J. Food, 13(3), 420-426.

Cornejo-Ramírez Y.I., Ramírez-Reyes F., Cinco-Moroyoqui F.J., Rosas-Burgos E.C., Martínez-Cruz O., CarvajalMillán E., Cárdenas-López J.L., and Wong-Corral F., 2016. Starch debranching enzyme activity and its effects on some starch physicochemical characteristics in developing substituted and complete triticales (X Triticosecale Wittmack). Cereal Chem., 93(1), 64-70.

Finnie S.M., Jeannotte R., and Faubion J.M., 2009. Quantitative characterization of polar lipids from wheat whole meal, flour, and starch. Cereal Chem., 86(6), 637-645.

Hayakawa K., Tanaka K., Nakamura T., Endo S., and Hoshino T., 1997. Quality characteristics of waxy hexaploid wheat (Triticum aestivum L.): properties of starch gelatinization and retrogradation. Cereal Chem., 74, 576-580.

Hizukuri S., Takeda Y., Yasuda M., and Suzuki A., 1981. Multi-branched nature of amylose and the action of debranching enzymes. Carbohyd. Res., 94(2), 205-213.

Inoue M. and Hirasawa I., 2013. The relationship between crystal morphology and XRD peak intensity on $\mathrm{CaSO}_{4} \times 2 \mathrm{H}_{2} \mathrm{O}$. J. Cryst. Growth, 380, 169-175.

Jane J., Chen Y.Y., Lee L.F., McPherson A.E., Wong K.S., Radosavljevic M., and Kasemsuwan T., 1999. Effects of amylopectin branch chain length and amylose content on the gelatinization and pasting properties of starch 1 . Cereal Chem., 76(5), 629-637.

Jane J., Kasemsuwan T., Leas S., Zobel H. and Robyt J.F., 1994. Anthology of starch granule morphology by scanning electron microscopy. Starch-Stärke, 46, 121-129.

Jeon J.S., Ryoo N., Hahn T.R., Walia H., and Nakamura Y., 2010. Starch biosynthesis in cereal endosperm. Plant Physiol. Bioch., 48(6), 383-392.

Jiamjariyatam R., Kongpensook V., and Pradipasena P., 2015. Effects of amylose content, cooling rate and aging time on properties and characteristics of rice starch gels and puffed products. J. Cereal Sci., 61, 16-25.

Kaur L., Singh J., Singh H., and McCarthy O.J., 2008. Starchcassia gum interactions: A microstructure-rheology study. Food Chem, 111(1), 1-10.

Kim J., Zhang C., and Shin M., 2015. Forming rice starch gels by adding retrograded and cross-linked resistant starch prepared from rice starch. Food Sci. Biotechnol., 24(3), 835-841.

Kim W., Johnson J.W., Graybosch R.A., and Gaines C.S., 2003. Physicochemical properties and end-use quality of wheat starch as a function of waxy protein alleles. J. Cereal Sci., 37(2), 195-204.

Mellado M.Z., Matus I.T., and Madariaga R.B., 2008. Background on triticale in Chile and other countries. Bulletin INIA, 183, 1-75.

Sang Y., Bean S., Seib P.A., Pedersen J., and Shi Y.C., 2008. Structure and functional properties of sorghum starches differing in amylose content. J. Agric. Food Chem., 56, 6680-6685.

SAS Institute, 2005. PROC user's manual, 8th version. Cary, NC: SAS Institute. Sasaki T., Yasui T., and Matsuki J., 2000. Effect of amylose content on gelatinization, retrogradation, and pasting properties of starches from waxy and nonwaxy wheat and their F1 seeds. Cereal Chem., 77(1), 58-63. 
Singh N., Singh J., Kaur L., Sodhi N.S., and Gill B.S., 2003. Morphological, thermal and rheological properties of starches from different botanical sources. Food Chem., 81(2), 219-231.

Song Y. and Jane J., 2000. Characterization of barley starches of waxy, normal, and high amylose varieties. Carbohyd. Polym., 41, 365-377.

Sun Q., Wu M., Bu X., and Xiong L., 2015. Effect of the amount and particle size of wheat fiber on the physicochemical properties and gel morphology of starches. PLoS ONE 10(6): e 0128665.

Ulbrich M., Wiesner I., and Flöter E., 2015. Molecular characterization of acid-thinned wheat, potato and pea starches and correlation to gel properties. Starch-Stärke, 67(5-6), 424-437.
Varughese G., Barker T., and Saari E., 1987. Triticale. CIMMYT, México, DF, pp. 32.

Yamin F.F., Lee M., Pollak L.M., and White P.J., 1999. Thermal properties of starch in corn variants isolated after chemical mutagenesis of inbred line B73. Cereal Chem., 76(2), 175-181.

Yoo S. and Jane J., 2002. Structural and physical characteristics of waxy and other wheat starches. Carbohyd. Polym., 49, 297-305.

Zhang H., Zhang W., Xu C., and Zhou X., 2013. Morphological features and physicochemical properties of waxy wheat starch. Int. J. Biol. Macromol., 62, 304-309.

Zhao H.J., Zou Q., and Zhang X.Y., 2003. Comparison between two wheat varieties with different spike type in carbohydrate metabolism during late growth period. Acta Agron. Sinica, 29(5), 676-681. 